\title{
Coherence Structure in the Discourse of Probability Modelling ${ }^{1}$
}

\author{
JANG, Hongshick \\ Hanyoung Foreign Language High School, 166 Sangil-dong, Gangdong-gu, \\ Seoul 134-710, Korea; Email: shick98@hotmail.com
}

(Received February 2, 2013; Revised February 7, 2013; Accepted March 21, 2013)

\begin{abstract}
Stochastic phenomena induce us to construct a probability model and structure our thinking; corresponding models help us to understand and interpret the reality. They in turn equip us with tools to recognize, reconstruct and solve problems. Therefore, various implications in terms of methodology as well as epistemology naturally flow from different adoptions of models for probability. Right from the basic scenarios of different perspectives to explore reality, students are occasionally exposed to misunderstanding and misinterpretations. With realistic examples a multi-faceted image of probability and different interpretation will be considered in mathematical modelling activities. As an exploratory investigation, mathematical modelling activity for probability learning was elaborated through semiotic analysis. Especially, the coherence structure in mathematical modelling discourse was reviewed form a semiotic perspective. The discourses sampled from group activities were analyzed on the basis of semiotic perspectives taxonomical coherence relations.
\end{abstract}

Keywords: probability models, mathematical discourse, coherence relations

MESC Classification: M14

MSC2010 Classification: 97M10

\section{INTRODUCTION}

With the steady advance of information technology, we are now living in a world characterized by complex systems which demand broader disciplines in mathematics. While we cope with the complex systems, we also begin to realize that there are fundamental limits: We also understand the necessity of mathematical formulation within the various type of uncertainty, which is characterized by probability measures. Since we are

1 This article will be presented at KSME 2013 Spring Conference on Mathematics Education at Ewha Womans Univ., Seodaemun-gu, Seoul 120-750, Korea; April 5-6, 2013. 
surrounded, both in everyday and professional life by some degree of uncertainty, disciplines for probability and statistics should supply the framework and tools for the task of inference and decision. In fact, probability and statistics are considered as fearsome and anxiety-evoking subjects for high school students. To improve the situation, I think we have three ways in concert.

First, to understand the difficulties that students have with comprehension of probability, we must identify the cognitive structure of mathematical process. Radford (2001) introduced a use of the "epistemic configuration of mathematical objects" construct, together with the processes in the onto-semiotic approach for a better understanding of mathematical tasks and cognitive processes. The Onto Semiotic Approach (OSA) defines as primary entities: Language, Situations, Procedures, Concepts, Propositions, Arguments (Godino, 2007, Gusmao, Santana, Cazorla \& Cajaraville, 2010). With OSA, we focus on these entities, using the "onto semiotic analysis", to characterize the institutional and personal meanings manifested during the mathematical activity and to analyze the semiotic conflicts during the resolution of concrete mathematical problems.

Second, we have to provide intelligently challenging environment where students have excess to more curiosity evoking contents of learning. The course could include the introduction of standard concepts with common probabilistic models. But it is not enough. In addition to standard techniques, they need good "models". We should incorporate more sophisticated models into the regular curriculum. Also, we know that much confusion - misinterpretations, misconceptions, fallacies and pitfalls abound in the study of probability. Most texts and exercise books neglect to deal with 'upsetting' contents. The justification is that students can understand and sort out those problems naturally after rigorous courses. However, teachers agree that if neglected, the misconceptions can't be dissolved just by studying formal subjects. Most students accept what they learned in mathematics classes as the whole truth without noticing that it occasionally contradict to intuition. If unchallenged by "upsetting" conflicts in a class room situation, they will only rely on intuitions giving up their knowledge from formal studies of probability. I believe it is best to let students confront problems and pitfalls in open and careful discussion and clear unnecessary potential 'upsets'.

Third, we have to encourage mathematical discourse which plays a great role in developing students' concepts. Active discourses help students with their reasoning and reflection on both the content as well as their understanding of it. Understanding a discourse is equivalent to constructing a coherent representation of that discourse. For example, coherence relations such as cause-consequence and claim-argument, is a necessary condition for a discourse representation to be coherent. The purpose of this paper is twofold. I will explore: 
(1) The representation of mathematical discourse in mathematical modelling practice for the formation and critical understanding probability concept.

(2) The relevance of applying taxonomic models of coherence relation for discord analysis by Sanders, Spooren \& Noordman (1992) to the mathematical modelling discourse.

\section{ONTO SEMIOTIC APPROACHES FOR PROBABILITY MODELLING}

\subsection{Interpretation of Probability Models}

Epistemologically, there is a basic difference between other domains of mathematics and that of probability. Probability objects, in contrast to other topics of mathematics, are never accessible by physical perception or by artifacts. The only way to have access to them is using signs and semiotic representations. For any modelling related to probability too, semiotic representations must be used even if there is the choice of the kind of semiotic representation. This specific epistemological situation of probability changes the cognitive use of signs. Elementary probability theory is an example for the analysis of basic epistemological problems of mathematical knowledge. Steinbring (2006) explained the sign system given as a concrete case by "fraction numerals". However, the concept of probability has to be distinguished from the signs, which can be understood simply as a fraction. The signs in probability theory are different from the objects/reference contexts (here for example dice, then mainly mental objects, or random structures).

According to the frame of the classic probability, the signs used to code probabilities are fractions that indicate the proportion of favorable to unfavorable cases. However, these "ideal" values must be carefully distinguished from the "true" probabilities of a chance experiment of randomness. With experiments, the probability can be estimated with the help of empirical law of large numbers, thus of observed relative frequencies.

As for the mathematical modelling of stochastic phenomena, the ever-present debate within epistemology of probability matters - objective vs. subjective. According to the objective definition, we conceive of probability as being something "out there" in the world to be analyzed in the same manner that we approach the physical world. Events have different and real physical probabilities that we can observe. On the other hand, we could choose to define probability not as an objective physical property in the world, but rather as a measure of man's subjective beliefs about what will happen. Within this subjective definition, there exists no such thing as physical probabilities "out there" in the 
world, because things in the world are all governed by the principle of causality that states nothing in the world is random or accidental. These problems of modelling make students modelling experience confusing.

With the given situation in the epistemological triangle in Figure 1, one can regard the ideal fraction numerals as examples for the vertex "mathematical signs/symbols" in order to determine the searched probabilities. And the patterns of relative frequencies (as empirically measured values), which can be observed in the real chance experiment, can be placed under the vertex "object/reference context".

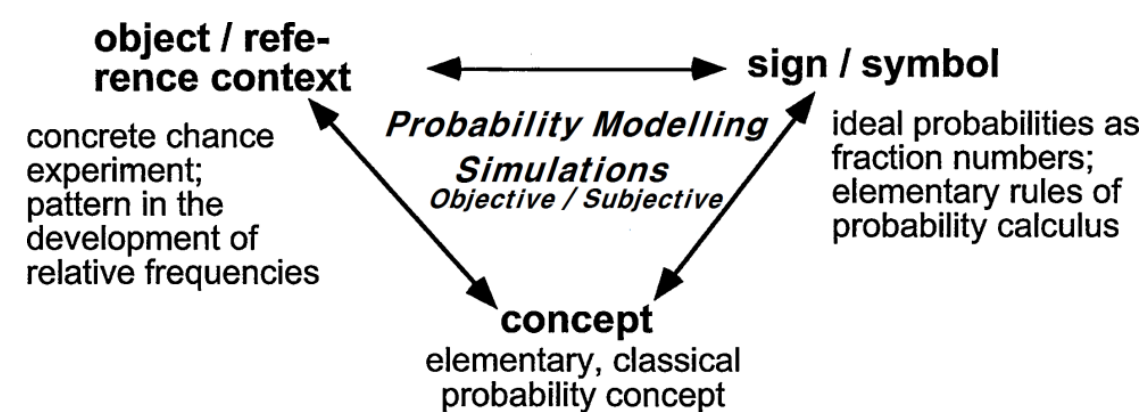

Figure 1. The mediation between ideal and empirical probability in probability modelling

How is a relation established between "object/reference context" and "mathematical signs/symbols"? How in the example of probability a relation is established between empirical and ideal probability? It would be too simple to claim that the (ideal) probability eventually becomes identical to the relative frequency (after a lot of trials). However, this relation is not a simple identity; it is based on a complex structure which is essentially determined by the epistemological conditions of the probability concept. The preliminary, rather direct, relation between relative frequency and classic probability in the frame of the empirical law of large numbers, is an assertion which must itself be mathematically analyzed and described according to mathematical models and rules. The modelling perspective achieves a synthesis between these two approaches. Resent didactic studies have led to successful teachings based on modelling process using simulations of models in statistics (cf. Caput, Grad \& Henry, 2011).

\subsection{Representation transformations in Probability Modelling}

According to Duval (2006), mathematical activity intrinsically consists in the transformation of representations, which consists of two types: Treatments and Conversions.

Treatments (curved arrows in the Figure 2) are transformations of representations that 
happen within the same register: for example, carrying out a algorithms while remaining strictly in the same notation system for representing the numbers, solving an equation or system of equations etc.

Conversions (straight arrows in Figure 2) are transformations of representation that consist of changing a register without changing the objects being denoted: for example, passing from the natural language statement of a relationship to its notation using letters, passing from the algebraic notation for an equation to its graphic representation, diagrams, etc.

\begin{tabular}{|c|c|c|}
\hline & $\begin{array}{l}\text { REPRESENTATIONS resulting from one the three } \\
\text { kinds of DISCURSIVE OPERATIONS: } \\
1 \text { Denotation of objects (names, marks...) } \\
2 \text { Statement of relations or properties } \\
\text { 3.Inference (deduction, computation...) }\end{array}$ & $\begin{array}{l}\text { NON-DISCURSIVE } \\
\text { REPRESENTATION } \\
\text { (Shape configurations } \\
\text { 1D } / 2 \mathrm{D}, 2 \mathrm{D} / \mathbf{2 D} \\
\text { 3D } / \mathbf{2 D} \text { ) }\end{array}$ \\
\hline $\begin{array}{l}\text { MULTI-FUNC } \\
\text { TIONAL } \\
\text { REGISTERS: } \\
\text { Processes } \\
\text { CANNOT BE } \\
\text { made into } \\
\text { algorithms }\end{array}$ & $\begin{array}{l}\text { IN NATURAL LANGUAGE: two non } \\
\text { equivalent modalities for expressing } \\
\text { ORALLY explanations, } \\
\text { (1) (2) } \\
6)(7)\end{array}$ & $\begin{array}{c}\rightarrow \text { NON-ICONIC: } \\
\text { geometrical figures } \\
\text { which can be } \\
\text { constructed with tool }\end{array}$ \\
\hline & $\begin{array}{l}\text { itional AUXILIARY Representations } \\
\text { No rules of combination (free support) }\end{array}$ & \\
\hline $\begin{array}{l}\text { MONO-FUNC } \\
\text { TIONAL } \\
\text { REGISTERS: } \\
\text { Most processes } \\
\text { are algorithmic }\end{array}$ & $\begin{array}{l}\downarrow \text { IN SYMBOLIC SYSTEMS } \\
\text { Only written: impossible to tell orally otherwise } \\
\text { than by spelling }\end{array}$ & $\begin{array}{l}\text { D2 COMBINATION of } \\
\text { D1 AND D0 SHAPES, } \\
\text { oriented (arrows) or }\end{array}$ \\
\hline
\end{tabular}

Figure 2. Classification of the registers in mathematical modelling processes.

According to his research, it appears that the cognitive processes in probability modelling are based on two quite different kinds of transformations of representations. Even if a single representation register is enough from a mathematical point of view, probability modelling activity also involves the simultaneous mobilization of at least two registers of representation, or the possibility of changing at any moment from one register to another. Every aspect of probability modelling can be possibly and plausibly explained by the above fifteen transformation. 


\section{METHODOLOGY}

\subsection{Discourse in Mathematical Modelling}

In the process of modelling, students use wide range of communication tools that go far beyond formal language. They use gestures, draw pictures and diagrams, make and use body language to draw attention. In talks, students are more inhibited and formal. In writing textual solutions, students are even more formal in translating their ideas into symbols and logic. And readers try to translate back. Mathematics in some sense has a common language: a language of symbols, technical definitions, computations, and logic which constitutes mathematical discourse as a whole. Thus, discourse in mathematical modelling is the window through which we can observe and understand the process of modeling activity. And for mathematics education, helping our students better master mathematical discourse is a major goal at all levels. The semiotic construction is powerful for modelling or reshaping our reality. Characteristic elements in mathematics such as abstraction, reason, objectivity and truth are viewed as particular types of semiotic choices. Abstraction is the re-contextualization where 'superfluous' information was discarded in the pursuit of knowledge. Objectivity is the organization of particular experimental and logical realms of meaning which are accompanied by a contracted interpersonal stance. From this view, objectivity becomes a 'valued' cultural product which is enacted semiotically. Reason is the valid rearrangement of relations which can be undertaken with available semiotic tools. And the truth is reduced to the nature of semiotic constructions found in the mathematical and scientific views of the world. Schonfield (2002) claims:

Students are much more likely to develop productive habits of mind when they have the opportunity to practice those habits, and to develop a disposition toward sense-making when they are members of communities that engage (successfully!) in such practices. As suggested above, crafting such communities takes a good deal of work.

For the investigation of mathematical discourses, several researchers (cf. O'Halloran, 2005) working on the social semiotic theory known as Systematic Functional Linguistics (SFL) investigated the educational implications of multisemiotic approach to mathematics.

The SFL approach to mathematics as a multisemiotic discourse is significant because it provides a framework to explain how language, mathematical symbolism and visual images function intersemiotically. Apart from concerning itself with a limited semantic domain, mathematical discourse is successful. While mathematics evolved from a written discourse, the interaction between a teacher 
and students involves spoken language as well as meta-language (verbalization of the symbolic and visual descriptions, gestures such as pointing, hand movements, facial expression, and body movements significant in classroom interactions). Brown (2000) and Sfard (2008) also suggested meaningful benefits from 'collective discourses' by reviewing how ideas can exist in discourses and social groupings. He provides detailed analyses of how people participate in the discourses of communities. His research provides an account of some basic ways in which individual learning arises from collaborative activities. It indicates how meaning can be encapsulated in symbols. It explains how children learn, and that creativity is possible, while suggesting ways to foster and to study learning. It describes mediations by which public discourses - as the foundational form of knowledge and group cognition-evolve and are individuated into private thinking. To nurture and encourage the discourse of modeling activity practically, Yackel (1996) suggested five Sociomathematical Norms:

(1) Students ask each other questions that press for mathematical reasoning, justification, and understanding.

(2) Students explain their solutions using mathematical argumentation.

(3) Students reach consensus using mathematical reasoning and proof.

(4) Students compare their strategies looking for mathematically important similarities and differences.

(5) Students use mistakes as an opportunity to rethink their conceptions of mathematical ideas and examine contradictions. Mistakes support new learning about mathematics.

\subsection{Coherence relations in Mathematical Discourse}

Understanding a discourse among students may be regarded as the construction of a mental representation of that discourse by the teachers. An acceptable discourse representation has a property that distinguishes it from the representation a teacher might make of a blind set of utterances: The representations of the fragments in the discourse should be linked coherently.

Sanders, Spooren \& Noordman (1992) conducted a classification experiment using segments of written discourse and extracted different classes of coherence relations distinguished in the taxonomy intuitively and psychologically plausible for practical application to the wide range of discourses.

Twelve class of coherence relations are postulated as cognitive primitives (Table 1 below).

The primary distinction in the taxonomy is that between causality and addition. Of the 
four logical operators, causality (implication) and addition (conjunction) are chosen as starting points for the taxonomy. Secondly, a 'pragmatic' relation refers to the illocutionary meaning of an utterance, whereas a 'semantic' relation refers to the locutionary meaning.

The third primitive is called order of the segments: Given the two basic operation, the speaker can connect two discourses segments in two orders. The fourth primitive is polarity. Positive relations are typically expressed by such conjuctions as and and because, where as negative relations are expressed by but and although, etc.

Table 1. Typology of Classes of Coherence Relations

\begin{tabular}{|c|c|c|c|c|c|}
\hline Class & Relations & $\begin{array}{c}\text { Basic } \\
\text { Operation }\end{array}$ & Source & Order & Polarity \\
\hline 1 & Cause/Consequence & Causal & semantic & basic & Positive \\
\hline 2 & $\begin{array}{c}\text { Contrative/Cause/ } \\
\text { Consequence }\end{array}$ & Causal & semantic & basic & Negative \\
\hline 3 & Consequence/Cause & Causal & semantic & non-basic & Positive \\
\hline 4 & $\begin{array}{l}\text { Contrastive/Consequence } \\
\text { /Cause }\end{array}$ & Causal & semantic & non-basic & Negative \\
\hline 5 & $\begin{array}{c}\text { Argument/Claim } \\
\text { Instrument/Goal } \\
\text { Condition/Consequence }\end{array}$ & Causal & pragmatic & Basic & Positive \\
\hline 6 & $\begin{array}{c}\text { Contrastive/Argument/ } \\
\text { Claim }\end{array}$ & Causal & pragmatic & Basic & Negative \\
\hline 7 & $\begin{array}{c}\text { Claim/Argument } \\
\text { Goal/Instrument } \\
\text { Consequence/Condition }\end{array}$ & Causal & pragmatic & non-basic & Positive \\
\hline 8 & $\begin{array}{c}\text { Contrastive Claim/ } \\
\text { Argument }\end{array}$ & Causal & pragmatic & non-basic & Negative \\
\hline 9 & List & Additive & semantic & n.a. & Positive \\
\hline 10 & $\begin{array}{l}\text { Exception } \\
\text { Opposition }\end{array}$ & Additive & semantic & n.a. & \\
\hline 11 & Enumeration & Additive & pragmatic & n.a. & Positive \\
\hline 12 & Exception & Additive & pragmatic & n.a. & Negative \\
\hline
\end{tabular}

On the basis of evidence with a priory, plausibility of above categorization of coherence relation, the taxonomy is an explicit theory of coherence that can generate predictions about discourse understanding. 


\section{METHODOLOGY AND RESULTS}

\subsection{Bertrand Paradox and Modelling}

In 1889, French mathematician Joseph Bertrand proposed a problem:

"What is the probability that the chord randomly chosen from a circle is longer than a side of the inscribed equilateral triangle of the circle?"

Solution 1. A chord is longer if the angle between the chord and the tangent line passing an endpoint of the chord on the circle is within the range $60^{\circ} \sim 120^{\circ}$. Thus, the probability is $1 / 3$.

Solution 2. A chord is longer if its midpoint lies within a concentric circle of half the original radius; so, since the area of small circle is a quarter that of the big circle, the probability is $1 / 4$.

Solution 3. A chord is longer if its midpoint lies on the inner half of the radius bisecting it; so, since the midpoint may lie anywhere on this radius, the probability is $1 / 2$.

It was called a paradox because the problem has at least three solutions that contradict to each other but each is derived from seemingly decent premises and reasoning. It is a well known example that shows "choosing by random" sometimes are not enough. In other words, we must know on which way to find probability and the reason for that statement are many different results of the problem what depends on which way we have used calculation.

\section{Scenario I}

A student ninja has been told to cut a pizza (circle with radius 1) because he needs practice (he needed practicing his sword maneuvers). The pizza is cut from the center (he has bad aim) so that the straight length of his slice varies, but each straight length should be parallel to each other (he wants such practice). The pizza company can only use pizzas with slices greater than $\sqrt{3}$. If the ninja cuts pizza too far away from the center the length is too small and pizza is wasted. What is the chance that a pizza becomes useful if it is cut randomly? 


\section{Discourse 1.}

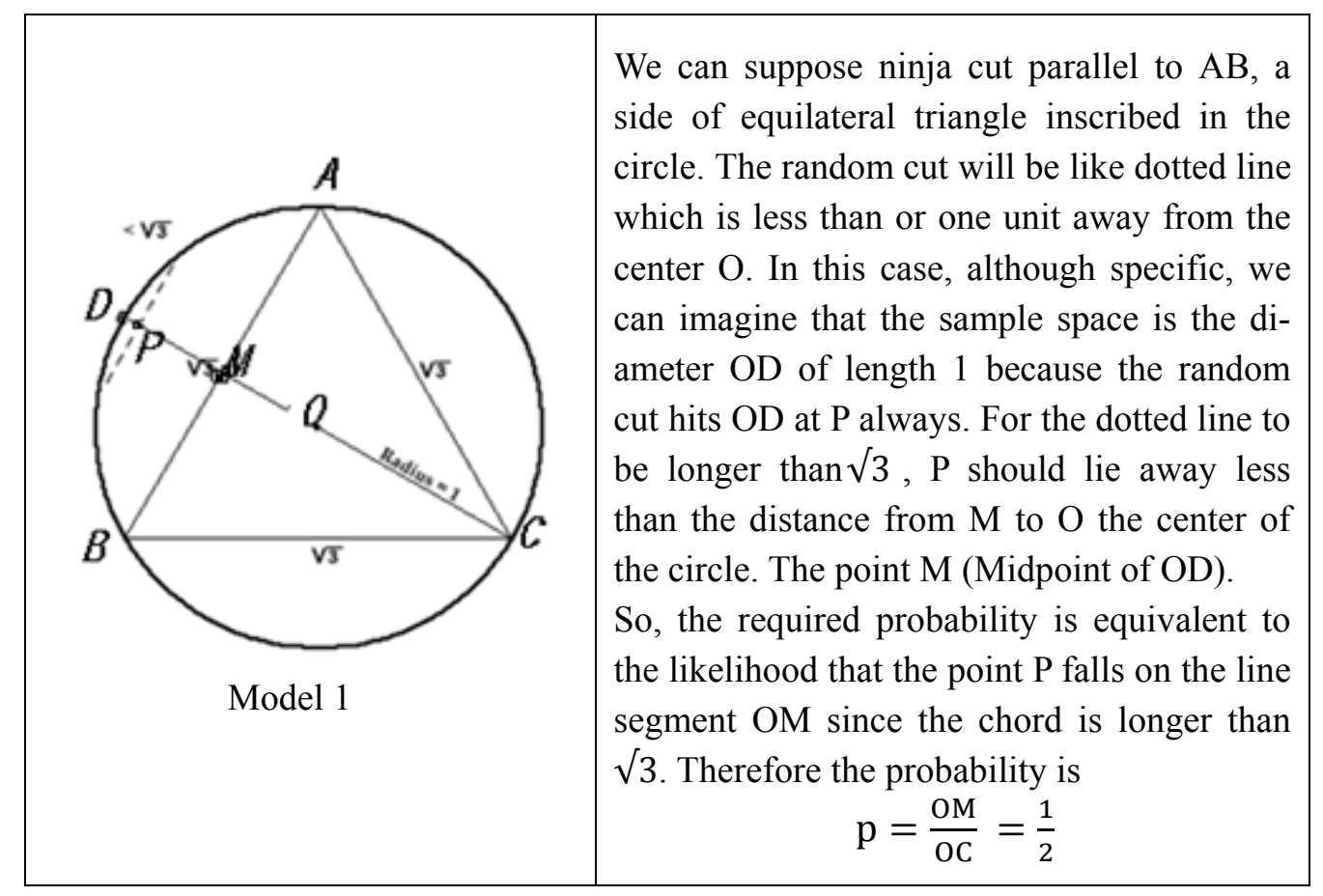

\section{Scenario II}

Imagine a circular lake with radius one mile. In this lake, lives a beautiful mermaid. And you want to take a picture of her when she comes into shore. The problem is that you don't know where exactly she will emerge on the lake shore. So you plant yourself at some point along the edge. The lens of the camera can only focus properly when the subject of the picture is further than root 3 miles away from you. For example, if distance between two of you is less than root 3 miles you have bad picture and distance greater than root 3 miles gives you a good picture. What is the chance that you take a good picture? 
Discourse 2.

Although the photographer takes a picture at ran-
dom place, we can choose one point $\mathrm{A}$, the vertex
of equilateral triangle inscribed without loss of gen-
erality. Suppose that the mermaid appears on the
point $\mathrm{P}$ on the circumference of the circle randomly.
Although point $\mathrm{P}$ is random, it is certain that the
point $\mathrm{P}$ lies on the arc $\mathrm{BC}$ to have the distance from
A to $\mathrm{P}$ is not less than $\sqrt{3}$. And the required proba-
bility is the ratio of the length of arc $\mathrm{BC}$, not major,
to the circumference of the lake. That is,
$\mathrm{p}=\frac{\text { the length of arc } \mathrm{BC}}{\text { the length of circumference }}=\frac{1}{3}$

\section{Scenario III}

Once upon a time there was monster living in the center of a dark crater. The monster had fire breath. Foolish pray would land in the crater and the monster would unleash his fire breath in a circular sweep. And of course, if the pray happened to be within his range, death. But if the prey was far enough away, it could avoid the spray by running perpendicular to the circle of fire. What is the chance that the pray could be caught?

\section{Discourse 3.}

Suppose a point $\mathrm{O}$ be the center of the small
concentric circle which is inscribed in the equi-
lateral triangle, which again is inscribed in a
circle of radius 1 . Now, for the chords of the
circle be not smaller than $\sqrt{3}$, the distance from
O to the midpoints of the chord P should be not
greater than $\frac{1}{2}$. Which means that P's should lie
in the circle of radius $\frac{1}{2}$. But, the sample space
of P is the inner part of big circle. And the re-
quired probability is given by
M $=\frac{\text { Area of small circle }}{\text { Area of big circle }}=\frac{\pi\left(\frac{1}{2}\right)^{2}}{\pi(1)^{2}}=\frac{1}{4}$




\subsection{Analysis: Coherence Structure, Treatment and Conversion}

Group activity based on a probability modeling project was designed and conducted. Each group consisted of 4 students of year 11 in HYFL and each group was supposed to model all of the problems of the 3 scenarioes exhaustively. 6 groups were assessed. The activity was conducted after the Bertrand Paradox was introduced.

Table 2. Typology of Classes of Coherence Relations with Hierarchy of Representation

\begin{tabular}{|c|c|c|}
\hline Summary specimens of Discourse(Textual) & $\begin{array}{c}\text { Coherence Relation } \\
\text { Class Type }\end{array}$ & $\begin{array}{l}\text { Treatment/ } \\
\text { Conversion }\end{array}$ \\
\hline $\begin{array}{l}\text { (Because of the condition 1) We can suppose ninja } \\
\text { cut parallel to } \mathrm{AB} \text {, a side of equilateral triangle in- } \\
\text { scribed in the circle }\end{array}$ & $\begin{array}{l}\text { Causal, Semantic } \\
\text { Basic order, } \\
\text { Positive (Class 1) }\end{array}$ & $\begin{array}{l}(3)(4)(7) \\
(11)(12)\end{array}$ \\
\hline $\begin{array}{l}\text { The random cut will be like dotted line which is less } \\
\text { than or one unit away from the center O. }\end{array}$ & $\begin{array}{l}\text { Additive Semantic } \\
\text { Positive (Class 9) }\end{array}$ & $(10)(13)$ \\
\hline $\begin{array}{l}\text { In this case, although specific, we can imagine that } \\
\text { the sample space is the diameter OD of length } 1 \text {, be- } \\
\text { cause a random cut hits OD at } P \text { always. }\end{array}$ & $\begin{array}{l}\text { Causal, Pragmatic } \\
\text { Nonbaic order } \\
\text { Negative (Class 8) }\end{array}$ & $\begin{array}{l}(3)(4)(7) \\
(11)(12)\end{array}$ \\
\hline $\begin{array}{l}\text { For the dotted line to be longer than } \sqrt{3}, \mathrm{P} \text { should lie } \\
\text { away less than the distance from } \mathrm{M} \text { to } \mathrm{O} \text { the center of } \\
\text { the circle. the point } \mathrm{M} \text { (Midpoint). }\end{array}$ & $\begin{array}{l}\text { Causal Pragmatic } \\
\text { Basic order Positive } \\
\text { (Class 5) }\end{array}$ & $\begin{array}{l}(9)(10)(1) \\
(3)\end{array}$ \\
\hline $\begin{array}{l}\text { The required probability is equivalent to the likeli- } \\
\text { hood that the point } \mathrm{P} \text { falls on the line segment OM, } \\
\text { since the chord is longer than } \sqrt{3} \text {. }\end{array}$ & $\begin{array}{l}\text { Causal, Semantic } \\
\text { Nonbasic order, } \\
\text { Positive } \\
\text { (Class 3) }\end{array}$ & $(10)(15)$ \\
\hline Therefore the probability is $\mathrm{p}=\frac{\mathrm{OM}}{\mathrm{OC}}=\frac{1}{2}$ & $\begin{array}{l}\text { Additive Pragmatic } \\
\text { Positive (Class 11) }\end{array}$ & $(5)(8)$ \\
\hline $\begin{array}{l}\text { Alhough the photographer take a picture at random } \\
\text { place, we can the vertex A of equilateral triangle in- } \\
\text { scribed without loss of generality. }\end{array}$ & $\begin{array}{l}\text { Causal, Pragmatic } \\
\text { Basic order, } \\
\text { Negative (Class 6) }\end{array}$ & $(3)(11)(12)$ \\
\hline $\begin{array}{l}\text { Although point } P \text { is random, it is certain that the point } \\
P \text { lies on the arc } B C \text { to have the distance from } A \text { to } P \\
\text { is not less than } \sqrt{3} \text {. }\end{array}$ & $\begin{array}{l}\text { Causal, Semantic } \\
\text { Basic order, } \\
\text { Negative (Class 2) }\end{array}$ & $\begin{array}{l}(2)(3)(4) \\
(10)\end{array}$ \\
\hline $\begin{array}{l}\text { And the probability is the ratio of the length of arc } \\
\mathrm{BC} \text {, not a major, to the circumference of the lake. }\end{array}$ & $\begin{array}{l}\text { Additive, Semantic } \\
\text { Negative (Class 10) }\end{array}$ & $(5)(6)$ \\
\hline $\begin{array}{l}\text { The length of OP become less than } \frac{1}{2} \text {, because the } \\
\text { length of the chord is not smaller than } \sqrt{3}\end{array}$ & $\begin{array}{l}\text { Causal Semantic } \\
\text { Nonbasic order, } \\
\text { Negative (Class 4) }\end{array}$ & $(1)(2)(5)$ \\
\hline $\begin{array}{l}\text { Which means that P's should lie in the circle of radi- } \\
\text { us } \\
\frac{1}{2} \text { for the length of OP less than } \frac{1}{2} \text {. }\end{array}$ & $\begin{array}{l}\text { Causal, Pragmatic } \\
\text { Non basic, Positive } \\
\text { (Class 7) }\end{array}$ & $(9)(10)$ \\
\hline $\begin{array}{l}\text { But, the sample space for } \mathrm{P} \text { is the inner part of big } \\
\text { circle. }\end{array}$ & $\begin{array}{l}\text { Additive, Pragmatic, } \\
\text { Negative Class } 12 .\end{array}$ & $(9)(15)$ \\
\hline
\end{tabular}


The activity was six hour out-of-class task after school over a one-week period designed to provide summative feedback to students according to the competence in developing a mathematical model as well as the solution summaries of textual discourse. During the activity, dialogues were observed and were incorporated for the final solution report. Three summaries out of six groups were chosen randomly as a specimen of the required analysis.

\section{CONCLUSION}

According to the analysis based on the taxonomy coherence relation and the representation transformation among registers, discourses in modelling probability can be effectively observed and meaningfully understood with reliable implication for assessment.

1. Most of the discourses sampled in summaries for each scenario are coherent.

2. There exists complicated hierarchies and transformation of representation in probability modelling, which calls for further investigation.

3. Semantic and Pragmatic relation, as a source of coherence relation, seems to be one of the most important factors of representation shift, which could provide teachers with the deep understanding of modelling probability.

4. To encourage the mathematical discourse of students, teachers should create an environment so that students can engage in group activities for cooperative learning.

\section{REFERENCES}

Brown, R. A. J. \& Renshaw, P. D. (2000). Collective argumentation: A sociocultural approach to reframing classroom teaching and learning. In: H. Cowie and G. van der Aalsvoort (Eds.), Social interaction in learning and instruction: The meaning of discourse for the construction of knowledge (pp. 52-66). Amsterdam: Pergamon Press.

Chaput, B.; Grad, C. J. \& Henry, M. (2011). Frequentist Approach: Modelling and Simulation in Statistics and Probability Teaching. In: Carmen Batanero et al. (Eds.), Teaching statistics in school mathematics - challenges for teaching and teacher education. A joint ICMI/IASE Study: The 18th ICMI Study (pp. 85-95). Berlin: Springer. ME 2012b.00960

Duval, R. (2006). A cognitive analysis of problems of comprehension in a learning mathematics. Educ. Stud. Math. 61(1-2), 103-131. ME 2006c.01581

Godino, J. D.; Batanero, C. \& Font,V. (2007) The onto-semiotic approach to research in mathematics education. ZDM 39(1-2), 127-135. ME 2009e.00177 
Gusmao, T.; Santana, E.; Cazorla, I. \& Cajaraville, J. (2010). A semiotic analysis of "Monica's random walk" Activity to teach basic concepts of probability. Paper presented at the Eighth International Conference on Teaching Statistics (ICOTS8, July, 2010). Available from: http://www.stat.auckland.ac.nz/ iase/publications/icots8/ICOTS8_C140_GUSMAO.pdf

O'Halloran, K. L. (2005). Mathematical discourse, language, symbolism and visual images. London and New York: Continuum.

Radford. L . (2001). On the relevance of Semiotics in Mathematics Education. Paper presented to the Discussion Group on Semiotics and Mathematics Education at the 25th PME International Conference, Netherlands, University of Utrecht, Netherlands; July 12-17, 2001.

Sanders, T.; Spooren, W. \& Noordman, L. (1992). Toward a Taxonomy of Coherence Relations. Discourse Processes 15(1), 1-35.

Sfard, A. (2008). Thinking as communicating: Human development, the growth of discourses and mathematizing. Cambridge, UK: Cambridge University Press. ME 2011d.00346

Schoenfeld, A. H. (2002). A highly interactive discourse structure. In: Social constructivist teaching, Vol. 9 (pp. 131-169). New York: Elsevier Science Ltd. http://umdscienceedseminar.pbworks.com/f/Schoenfeld+(2002).pdf

Steinbring, H. (2006). What makes a sign a mathematical sign? An epistemological perspective on mathematical interaction. Educ. Stud. Math. 61(1-2), 133-162. ME 2006c.01718

Yackel, E. \& Cobb, P. (1996). Sociomathematical norms, argumentation, and autonomy in mathematics. J. Res. Math.Educ. 27(4), 458-477. ME 1997f.03754 